J. L. Sánchez-Quesada $\cdot$ S. Benítez $\cdot$ A. Pérez $\cdot$

A. M. Wagner - M. Rigla • G. Carreras $\cdot$ L. Vila $\cdot$

M. Camacho $\cdot$ R. Arcelus $\cdot$ J. Ordóñez-Llanos

\title{
The inflammatory properties of electronegative low-density lipoprotein from type 1 diabetic patients are related to increased platelet-activating factor acetylhydrolase activity
}

Received: 7 April 2005 / Accepted: 31 May 2005 / Published online: 18 August 2005

(C) Springer-Verlag 2005

\begin{abstract}
Aims/hypothesis: Chemical and biological characteristics of LDL(-) from type 1 diabetic subjects were analysed. The diabetic patients were studied during poor and optimised glycaemic control. Materials and methods: Total LDL was subfractionated into electropositive $\operatorname{LDL}(+)$ and electronegative $\operatorname{LDL}(-)$ by anion exchange chromatography and the lipid and protein composition of the two determined. Results: LDL(-) differed from LDL(+) in that it had higher triglyceride, non-esterified fatty acids, apoE, apoCIII and platelet-activating factor acetylhydrolase (PAF-AH), as well as lower apoB relative content. No evidence of increased oxidation was observed in $\operatorname{LDL}(-)$. $\operatorname{LDL}(-)$ increased two-fold the release of interleukin 8 (IL-8) and monocyte chemotactic protein 1 (MCP-1) in endothelial cells, suggesting an inflammatory role. Optimisation of
\end{abstract}

J. L. Sánchez-Quesada · R. Arcelus · J. Ordóñez-Llanos

Department of Biochemistry,

Hospital de la Santa Creu i Sant Pau,

Barcelona, Spain

J. L. Sánchez-Quesada · S. Benítez · L. Vila · M. Camacho Research Institute, Hospital de la Santa Creu i Sant Pau,

Barcelona, Spain

A. Pérez · A. M. Wagner · M. Rigla

Department of Endocrinology and Nutrition,

Hospital de la Santa Creu i Sant Pau,

Barcelona, Spain

G. Carreras

Department of Paediatrics, Hospital de la Santa Creu i Sant Pau, Barcelona, Spain

J. Ordóñez-Llanos

Department of Biochemistry and Molecular Biology,

Universitat Autònoma de Barcelona,

Barcelona, Spain

J. Ordóñez-Llanos $(\bowtie)$

Servei de Bioquímica, Hospital de la Santa Creu i Sant Pau,

C/Antoni María Claret 167,

08025 Barcelona, Spain

e-mail: jordonez@hsp.santpau.es

Tel.: +34-93-2919451

Fax: +34-93-2919196 glycaemic control after insulin therapy decreased the proportion of $\operatorname{LDL}(-)$, but did not modify the composition of LDL subfractions, except for a decrease in PAF-AH activity in $\operatorname{LDL}(-)$. The possibility that $\operatorname{LDL}(-)$ could be generated by non-enzymatic glycosylation was studied. Fructosamine and glycated LDL content in LDL subfractions from type 1 diabetic patients was greater than in LDL subfractions isolated from normoglycaemic subjects, and decreased after glycaemic optimisation in both subfractions. However, no difference was observed between LDL $(+)$ and LDL $(-)$ before and after insulin therapy. Conclusions/ interpretation: These results provide evidence that LDL $(-)$ is not produced by glycosylation. Nevertheless, LDL(-) from diabetic patients displays inflammatory potential reflected by the induction of chemokine release in endothelial cells. This proatherogenic effect could be related to the high PAF-AH activity in $\operatorname{LDL}(-)$.

Keywords Atherosclerosis - Electronegative low-density lipoprotein - Inflammation - Type 1 diabetes mellitus

\begin{abstract}
Abbreviations AP-1: activating protein 1 apo: apolipoprotein · ECGS: endothelial cell growth supplement - FH: familial hypercholesterolaemia - FPLC: Fast Protein Liquid Chromatography $\cdot \operatorname{LDL}(-)$ : electronegative low-density lipoprotein $\cdot \operatorname{LDL}(+)$ : electropositive low-density lipoprotein - LDH: lactate dehydrogenase $\cdot$ MCP-1: monocyte chemotactic protein . MDA: malondialdehyde $\cdot$ NF- $\mathrm{kB}$ : nuclear factor $\mathrm{kB}$. oxLDL: oxidised low-density lipoprotein PAF-AH: platelet activating factor acetylhydrolase $\cdot$ PVDF: polyvinylidene difluoride - VCAM: vascular cell adhesion molecule
\end{abstract}

\section{Introduction}

Diabetes mellitus is an independent risk factor for the development of atherosclerosis, which, in turn, is the leading cause of death in diabetic subjects [1]. Beyond the frequent quantitative abnormalities in the lipid profile of diabetic 
patients [2], qualitative modifications in lipoproteins have been described. Modification of LDL plays a key role in the pathogenesis of atherosclerosis [3]. Increased concentrations of several forms of modified LDL have been detected in plasma of diabetic patients, including oxidised [4], glycosylated [5], desialylated [6] and small dense LDL particles [7]. A common feature of these modified forms of LDL is an increase in their electronegativity. Making use of this characteristic, an electronegative modified LDL subfraction (LDL[-]) can be isolated from human plasma by anion exchange chromatography [8]. LDL $(-)$ exhibits a variety of atherogenic and inflammatory properties [9], including abnormal density distribution [10], impaired affinity for the LDL receptor $[8,11]$, cytotoxicity $[12,13]$, apoptosis [14] and induction of inflammatory molecules production in cultured endothelial cells, such as interleukin-8 (IL-8), monocyte chemotactic protein (MCP-1) [15, 16] and TNF- $\alpha$-induced vascular cell adhesion molecule (VCAM) [17]. Moreover, the proportion of LDL $(-)$ is increased in diseases with high cardiovascular risk such as familial hypercholesterolaemia $(\mathrm{FH})[11,18]$, hypertriglyceridaemia [10], renal failure disease [19] and type 1 and type 2 diabetes mellitus [20-23]. Our group previously reported that optimisation of glycaemic control with intensive insulin therapy decreases the proportion of LDL $(-)$ in subjects with type 1 diabetes [20,21], which led us to hypothesise that non-enzymatic glycosylation could be involved in the generation of LDL(-) in these patients. Although extensive characterisation of LDL(-) from normolipaemic and FH subjects has been reported [8-17], no data exist on the physicochemical characteristics of LDL (-) from diabetic subjects. Thus, the aim of the current work was to ascertain whether non-enzymatic glycosylation of LDL could directly induce the formation of LDL(-), thereby causing an increased proportion of LDL(-) in type 1 diabetic patients, and to determine the physicochemical and biological characteristics of $\operatorname{LDL}(-)$ isolated from these patients.

\section{Subjects and methods}

Subjects and experimental design Type 1 diabetic subjects $(n=60)$ were selected on the basis of their $\mathrm{HbA}_{1} \mathrm{c}$ levels ( $>8.5 \%$, non-ketoacidosis), short diabetes duration (0-36 months) and lack of chronic diabetic complications. The type of diabetes was defined according to the National Diabetes Data Group [24] and inclusion criteria have been described elsewhere [21]. All patients were included in an intensive insulin therapy programme, as described [20], and optimised glycaemic control was regarded as achieved when $\mathrm{HbA}_{1} \mathrm{c}$ was fewer than $7 \%$. Healthy normolipidaemic and normoglycaemic subjects were selected as a control group, as described [21]. Informed consent of the patients was obtained and the study was approved by the hospital Ethics Committee. Investigations were in accordance with the Declaration of Helsinki. Fasting plasma was obtained in EDTA-containing Vacutainer tubes and stored at $-80^{\circ} \mathrm{C}$ for a period no longer than 120 days. After thawing, plasma aliquots were pooled (90-120 $\mathrm{ml}$ of plasma for each experiment from at least 10 different subjects) and total LDL (density range: $1.019-1.050 \mathrm{~g} / \mathrm{ml}$ ) was isolated by sequential ultracentrifugation at $4^{\circ} \mathrm{C}$ in presence of $1 \mathrm{mmol} /$ 1 EDTA. Two fractions of LDL were isolated by preparative anion-exchange chromatography using a multistep gradient in an FPLC system (Amersham, Uppsala, Sweden), as described [16]. Electropositive LDL (LDL[+]) eluted at $0.22 \mathrm{~mol} / 1 \mathrm{NaCl}$ and LDL(-) eluted at $0.5 \mathrm{~mol} / 1 \mathrm{NaCl}$ and both were detected at $280 \mathrm{~nm}$. Six independent experiments, containing plasma mixtures from type 1 diabetic patients with poor glycaemic control $\left(\mathrm{HbA}_{1} \mathrm{c}\right.$ 8.5-13.8\%) and plasma mixtures from the same subjects after optimisation of glycaemic control $\left(\mathrm{HbA}_{1} \mathrm{c} 5.5-6.9 \%\right)$, were performed. A plasma mixture from control subjects was included in each experiment.

In vitro modification of $L D L$ Oxidised LDL (oxLDL) was obtained by incubation of LDL from control subjects dialysed against PBS with $10 \mu \mathrm{mol} / 1 \mathrm{CuSO}_{4}$ for $24 \mathrm{~h}$. Malondialdehyde (MDA) content of oxLDL preparations was higher than $10 \mathrm{nmol} \mathrm{MDA} / \mathrm{mg}$ apoB. LDL dialysed in $10 \mathrm{mmol} / 1$ Tris and $1 \mathrm{mmol} / \mathrm{l}$ EDTA was glycated by incubation at $37^{\circ} \mathrm{C}$ with $50 \mathrm{mmol} / 1$ glucose for increasing times (up to 12 days), in the presence of $2 \mu \mathrm{mol} / 1$ butylated hydroxytoluene.

Lipid and apoprotein composition Major lipids (free and esterified cholesterol, phospholipids, triglyceride and NEFA) and apoproteins (apoB, apoE, apoC-III, apoC-II, apoA-I and apo[a]) were determined by commercial methods (Roche Diagnostics, Basel, Switzerland; Wako Chemicals, Neuss, Germany) in a Hitachi 911 autoanalyser (Roche) as described [16]. Antioxidant content ( $\alpha$-tocopherol, $\alpha$ carotene, $\beta$-carotene and lycopene) was determined by reverse-phase high-performance liquid chromatography (RP-HPLC) with a diode array detector [25]. Malondialdehyde (MDA) content was quantified by RP-HPLC and fluorometric detection [26].

Electrophoretic characterisation LDL particle size (expressed as $\mathrm{nm}$ ) was evaluated by non-denaturing polyacrylamide gradient gel electrophoresis [10]. ApoB integrity was assessed by polyacrylamide electrophoresis in the presence of sodium dodecyl sulphate (SDS-PAGE) in 4-20\% gradient gels (BioRad, Hercules, CA, USA). Increased electronegativity of $\operatorname{LDL}(-)$ was confirmed by agarose electrophoresis (Biomidi, Toulouse, France).

LDL susceptibility to oxidation Oxidisability of LDL subfractions $(50 \mu \mathrm{g} / \mathrm{ml}$ apoB in PBS) was assessed by monitoring at $234 \mathrm{~nm}$ the formation of conjugated dienes induced at $30^{\circ} \mathrm{C}$ by $2.5 \mu \mathrm{mol} / 1 \mathrm{CuSO}_{4}$, as described [20], and lag-phase time (min) was determined [27].

Platelet-activating factor acetylhydrolase $(P A F-A H)$ activity A commercial colorimetric assay (Cayman Chemical, Ann Arbor, MI, USA), using 2-thio-PAF as a substrate, was performed. LDL subfractions $(10 \mu \mathrm{l}$ of LDL at $0.25 \mathrm{~g} /$ 
Table 1 LDL(-) proportion and glycaemic control parameters of LDL subfractions from normolipaemic subjects and type 1 diabetic patients in poor and good glycaemic control

\begin{tabular}{|c|c|c|c|c|c|c|}
\hline \multirow[t]{4}{*}{$\% \operatorname{LDL}(-)$} & \multirow{2}{*}{\multicolumn{2}{|c|}{ Control group }} & \multicolumn{4}{|c|}{ Type 1 diabetes } \\
\hline & & & \multirow{2}{*}{\multicolumn{2}{|c|}{$\begin{array}{l}\text { Poor glycaemic control } \\
16.1 \pm 5.0^{\mathrm{a}}\end{array}$}} & \multirow{2}{*}{\multicolumn{2}{|c|}{$\begin{array}{l}\text { Good glycaemic control } \\
12.8 \pm 4.8^{\mathrm{a}, \mathrm{b}}\end{array}$}} \\
\hline & \multicolumn{2}{|l|}{$5.4 \pm 2.4$} & & & & \\
\hline & $\mathrm{LDL}(+)$ & $\operatorname{LDL}(-)$ & $\mathrm{LDL}(+)$ & LDL(-) & $\mathrm{LDL}(+)$ & $\operatorname{LDL}(-)$ \\
\hline$\%$ Glycated LDL & $4.1 \pm 1.7$ & $5.4 \pm 3.2$ & $8.9 \pm 3.1^{\mathrm{a}}$ & $6.9 \pm 3.1$ & $5.9 \pm 2.0^{\mathrm{b}}$ & $5.2 \pm 2.0^{\mathrm{b}}$ \\
\hline Fructosamine (mol/mol apoB) & $8.1 \pm 2.1$ & $8.6 \pm 3.3$ & $14.6 \pm 2.0^{\mathrm{a}}$ & $16.9 \pm 2.7^{\mathrm{a}}$ & $9.9 \pm 2.2^{\mathrm{b}}$ & $8.9 \pm 2.2^{\mathrm{b}}$ \\
\hline
\end{tabular}

${ }_{1}^{\mathrm{a}} p<0.05$ vs control group

${ }^{\mathrm{b}} p<0.05$ vs poor glycaemic control

1 apoB) were assayed as previously described [28]. Absorbance was measured at $414 \mathrm{~nm}$ at increased times in a microtitre plate and the slope was used to calculate

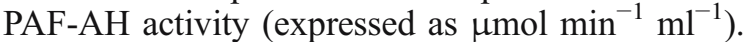

Western blot of LDL subfractions was performed to confirm PAF-AH activity results. LDL was electrophoresed in $4-20 \%$ SDS-PAGE gels (BioRad) and proteins were transferred to a polyvinylidene difluoride membrane (Immunblot PVDF, BioRad) in a Mini Trans-blot electrophoretic transfer cell (BioRad). PVDF membranes were revealed with PAF-AH polyclonal antiserum (Cayman Chemical) as described [28].

Glycaemic parameters The proportion of glycated LDL was determined in each LDL subfraction by affinity chromatography using agarose-coupled phenyl boronate (Glycogel II; Pierce, Rockford, IL, USA). Chromatography was adapted to an automated FPLC chromatographic system (Amersham) as described [21] with minor modifications. Briefly, LDL was dialysed against binding buffer (250 mmol/l ammonium acetate, $50 \mathrm{mmol} / 1 \mathrm{MgCl}_{2}, \mathrm{pH}$ 8.05 ) and $100 \mu \mathrm{g}$ of apoB (in $200 \mu \mathrm{l}$ ) were injected into the column and allowed to interact with resin for $5 \mathrm{~min}$ (flow rate: $0.02 \mathrm{ml} / \mathrm{min}$ ). The unbound fraction (non-glycated LDL) was then eluted with binding buffer at $1 \mathrm{ml} / \mathrm{min}$. The bound fraction (glycated LDL) was eluted with elution buffer $(200 \mathrm{mmol} / \mathrm{l}$ sorbitol, $100 \mathrm{mmol} / \mathrm{l}$ Tris, $\mathrm{pH} 8.5)$ at $1 \mathrm{ml} / \mathrm{min}$. Glycated and non-glycated LDL peaks were detected at $280 \mathrm{~nm}$ and peak areas were manually integrated.
Fructosamine content in LDL subfractions was quantified by a commercial method (Roche Diagnostics) in a Cobas Integra autoanalyser using LDL at a concentration of $0.5 \mathrm{~g} / \mathrm{l}$ apoB.

Inflammatory effect on cultured endothelial cells Human umbilical vein endothelial cells (HUVEC) were isolated by collagenase digestion and cultured as described [16]. Cells in confluent stage (1-2 passages) were seeded in sixwell plates at 150,000 cells/well. LDLs were added for $24 \mathrm{~h}$ at $100 \mathrm{mg}$ apoB/l in 199 medium containing $1 \% \mathrm{FCS}$ without heparin and endothelial cell growth supplement (ECGS). LDLs were previously dialysed against 199 medium and filtered through $0.22 \mu \mathrm{m}$. TNF- $\alpha(20 \mu \mathrm{g} / \mathrm{l})$ and oxLDL (100 mg apoB/l) were used as positive controls for chemokine production. Cell viability was evaluated by optic microscopy and lactate dehydrogenase (LDH) assay. After 24-h incubation of HUVEC with LDLs or TNF- $\alpha$, supernatant aliquots were frozen at $-80^{\circ} \mathrm{C}$ for IL-8 and MCP-1 measurements. IL-8 (Diaclone, Besançon, France) and MCP-1 (Endogen, Woburn, MA, USA) released in the media were quantified by ELISA. Results were expressed as $\mathrm{ng} / 10^{5}$ cells.

Transcription factor studies HUVEC were cultured in Petri dishes at 1,000,000 cells/well and LDL (100 mg apoB/l) or IL-1 $\beta$ (10 U/ml, positive control) was added for $4 \mathrm{~h}$ of incubation. Nuclear protein extracts were obtained using the TransFactor Extraction Kit (BD-Clontech, Palo Alto,
Fig. 1 Representative agarose gel electrophoresis of in vitroglycated LDL and LDL subfractions. $\operatorname{LDL}(+)$ and $\operatorname{LDL}(-)$ subfractions were isolated as described in Subjects and Methods. Total LDL was glycated by incubation at $37^{\circ} \mathrm{C}$ with $50 \mathrm{mmol} / 1$ glucose for increasing times, in the presence of EDTA 1 and $2 \mu \mathrm{mol} / 1$ butylated hydroxytoluene. Fructosamine content and glycated LDL proportion were measured as described in Subjects and Methods

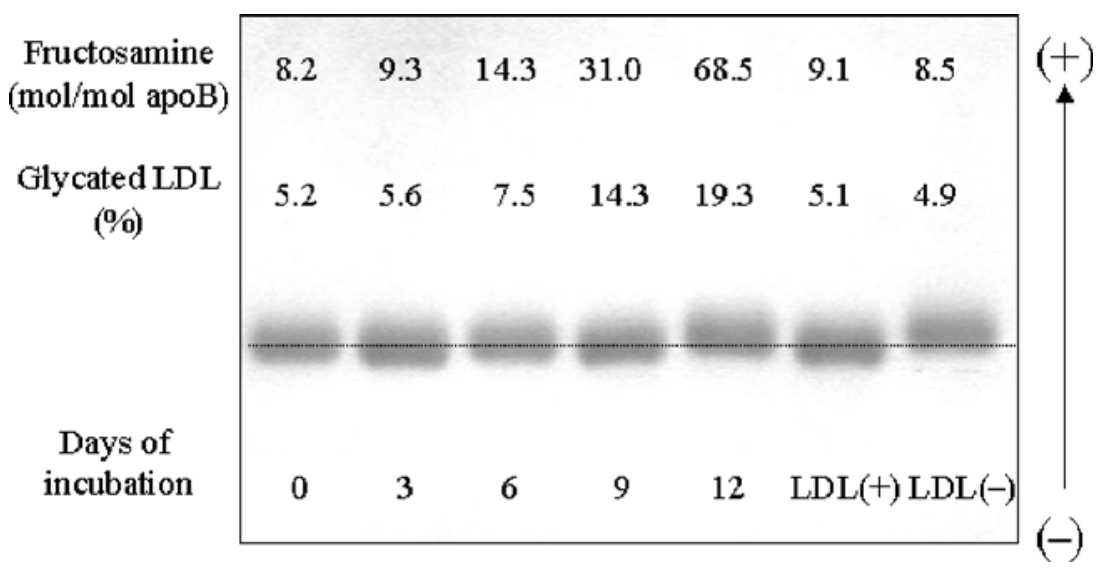


Table 2 Lipid and apoprotein composition of LDL subfractions from control subjects and type 1 diabetic patients in poor and good glycaemic control

Major lipids and apoB are expressed as percentage of total LDL mass. NEFA is expressed as $\mathrm{mol} / \mathrm{mol}$ apoB. ApoE and apoC-III are expressed as mmol/ mol apoB ${ }_{p}<0.05$ vs $\operatorname{LDL}(+)$

\begin{tabular}{|c|c|c|c|c|c|c|}
\hline & \multirow{2}{*}{\multicolumn{2}{|c|}{ Control group }} & \multicolumn{4}{|c|}{ Type 1 diabetes } \\
\hline & & & \multicolumn{2}{|c|}{ Poor glycaemic control } & \multicolumn{2}{|c|}{ Good glycaemic control } \\
\hline & $\operatorname{LDL}(+)$ & $\operatorname{LDL}(-)$ & $\operatorname{LDL}(+)$ & $\operatorname{LDL}(-)$ & $\operatorname{LDL}(+)$ & LDL(-) \\
\hline Total cholesterol & $40.9 \pm 2.2$ & $41.0 \pm 1.6$ & $39.8 \pm 2.2$ & $41.3 \pm 2.5$ & $40.3 \pm 1.7$ & $41.8 \pm 2.5$ \\
\hline Esterified cholesterol & $29.5 \pm 1.8$ & $29.4 \pm 1.2$ & $28.7 \pm 1.6$ & $30.1 \pm 2.0$ & $28.7 \pm 1.4$ & $30.5 \pm 2.1$ \\
\hline Free cholesterol & $11.4 \pm 0.6$ & $11.6 \pm 0.5$ & $11.1 \pm 0.8$ & $11.2 \pm 0.7$ & $11.7 \pm 1.1$ & $11.3 \pm 0.8$ \\
\hline Triglyceride & $6.7 \pm 1.8$ & $8.9 \pm 1.6^{\mathrm{a}}$ & $7.0 \pm 0.9$ & $9.7 \pm 1.7^{\mathrm{a}}$ & $6.0 \pm 0.5$ & $7.9 \pm 1.1^{\mathrm{a}}$ \\
\hline Phospholipids & $26.9 \pm 2.0$ & $27.3 \pm 1.4$ & $26.9 \pm 2.5$ & $26.6 \pm 2.3$ & $28.1 \pm 2.5$ & $26.7 \pm 2.1$ \\
\hline ApoB & $25.7 \pm 1.8$ & $22.2 \pm 1.7^{\mathrm{a}}$ & $26.4 \pm 2.6$ & $23.4 \pm 2.4^{\mathrm{a}}$ & $25.6 \pm 1.4$ & $23.6 \pm 2.0^{\mathrm{a}}$ \\
\hline NEFA & $14.4 \pm 8.2$ & $39.6 \pm 13.7^{\mathrm{a}}$ & $13.7 \pm 6.0$ & $27.4 \pm 10.4^{\mathrm{a}}$ & $13.2 \pm 9.2$ & $31.3 \pm 15.6^{\mathrm{a}}$ \\
\hline ApoE & $11 \pm 6$ & $129 \pm 44^{\mathrm{a}}$ & $10 \pm 10$ & $120 \pm 107^{\mathrm{a}}$ & $8 \pm 9$ & $120 \pm 82^{\mathrm{a}}$ \\
\hline ApoC-III & $29 \pm 14$ & $296 \pm 175^{\mathrm{a}}$ & $40 \pm 15$ & $311 \pm 126^{\mathrm{a}}$ & $33 \pm 26$ & $325 \pm 250^{\mathrm{a}}$ \\
\hline
\end{tabular}

CA, USA). The involvement of transcription factors was studied using an ELISA-based commercial method (BD Mercury TransFactor Kit, Profiling Kit - Inflammation 1 and Profiling Kit-Inflammation 2; BD-Clontech), which detects DNA-protein interactions. Twenty micrograms of nuclear proteins were used for the assay and the manufacturer's instructions were followed. Results were expressed as increment versus control cells (unstimulated cells). Profiling Kit-Inflammation 1 measures NF-kB p65, NF-kB p50, c-Fos, c-Rel, CREB-1 and ATF2, whereas Profiling Kit-Inflammation 2 measures c-Fos, FosB, Sp-1, STAT1, JunD and c-Jun.

Statistical analysis Results are expressed as means SD. Differences between groups were tested with the Wilcoxon T-test for paired data (LDL $[+]$ vs LDL[ $[-]$ isolated from the same plasma mixture) and Mann-Whitney $U$-test for unpaired data. A value of $p<0.05$ was considered significant.

\section{Results}

The LDL(-) proportion observed in plasma pools from type 1 diabetic patients in poor glycaemic control was three times higher than that observed in plasma pools from control subjects. Insulin therapy decreased the $\operatorname{LDL}(-)$ proportion in type 1 diabetic patients, though without reaching a percentage similar to that in controls (Table 1). The proportion of glycated LDL and fructosamine content was also greater in samples from poorly controlled type 1 diabetic subjects than in control samples, and optimisation of glycaemic control diminished both parameters of glycation (Table 1). However, no difference was observed between $\operatorname{LDL}(+)$ and $\operatorname{LDL}(-)$ in either of the groups studied, indicating that LDL(-) from type 1 diabetic subjects was not generated by direct non-enzymatic glycosylation. This was supported by in vitro experiments showing that the fructosamine content and the glycated LDL proportion required to achieve the same electrophoretic mobility as LDL(-) are much higher than the glycaemic parameters determined in LDL $(-)$. A representative agarose gel electrophoresis including fructosamine content and percentage of glycated LDL values of native LDL glycated 'in vitro' after several days of incubation with $50 \mathrm{mmol} / \mathrm{l}$ glucose is shown in Fig. 1.

Lipid and apoprotein composition of LDL subfractions is shown in Table 2. Both in control samples and in diabetic samples during poor and good glycaemic control, LDL $(-)$

Table 3 Antioxidant content, oxidative parameters, PAF-AH activity and particle size of LDL $(+)$ and LDL $(-)$ subfractions from control subjects and type 1 diabetic patients in poor and good glycaemic control

\begin{tabular}{|c|c|c|c|c|c|c|}
\hline & \multirow{2}{*}{\multicolumn{2}{|c|}{ Control group }} & \multicolumn{4}{|c|}{ Type 1 diabetes } \\
\hline & & & \multicolumn{2}{|c|}{ Poor glycaemic control } & \multicolumn{2}{|c|}{ Good glycaemic control } \\
\hline & $\mathrm{LDL}(+)$ & $\operatorname{LDL}(-)$ & $\mathrm{LDL}(+)$ & $\operatorname{LDL}(-)$ & $\operatorname{LDL}(+)$ & $\operatorname{LDL}(-)$ \\
\hline$\alpha$-Tocopherol & $7.7 \pm 1.4$ & $7.2 \pm 1.9$ & $7.0 \pm 2.1$ & $6.9 \pm 3.1$ & $7.2 \pm 1.9$ & $7.3 \pm 1.5$ \\
\hline$\alpha$-Carotene & $0.04 \pm 0.02$ & $0.04 \pm 0.01$ & $0.03 \pm 0.01$ & $0.03 \pm 0.01$ & $0.04 \pm 0.02$ & $0.02 \pm 0.02$ \\
\hline$\beta$-Carotene & $0.19 \pm 0.08$ & $0.22 \pm 0.19$ & $0.20 \pm 0.09$ & $0.19 \pm 0.12$ & $0.22 \pm 0.11$ & $0.22 \pm 0.15$ \\
\hline Lag phase & $46.6 \pm 9.4$ & $74.0 \pm 13.4^{\mathrm{a}}$ & $58.5 \pm 7.8$ & $74.5 \pm 13.3^{\mathrm{a}}$ & $46.5 \pm 9.9$ & $58.1 \pm 7.7^{\mathrm{a}}$ \\
\hline PAF-AH & $1.08 \pm 0.13$ & $5.63 \pm 0.67^{\mathrm{a}}$ & $0.85 \pm 0.24$ & $6.98 \pm 0.43^{\mathrm{a}}$ & $0.88 \pm 0.28$ & $4.88 \pm 0.69^{\mathrm{a}, \mathrm{b}}$ \\
\hline LDL size & $26.6 \pm 0.3$ & $26.4 \pm 0.5$ & $26.4 \pm 0.3$ & $26.5 \pm 0.4$ & $26.5 \pm 0.3$ & $26.4 \pm 0.5$ \\
\hline
\end{tabular}

Antioxidants and MDA are expressed as mol/mol apoB. Lag phase is expressed as min. PAF-AH activity is expressed as $\mu \mathrm{mol} \mathrm{min}{ }^{-1} \mathrm{ml}^{-1}$. LDL size is expressed as $\mathrm{nm}$

${ }^{\mathrm{a}} p<0.05$ vs $\operatorname{LDL}(+)$

${ }^{\mathrm{b}} p<0.05$ vs poor control 


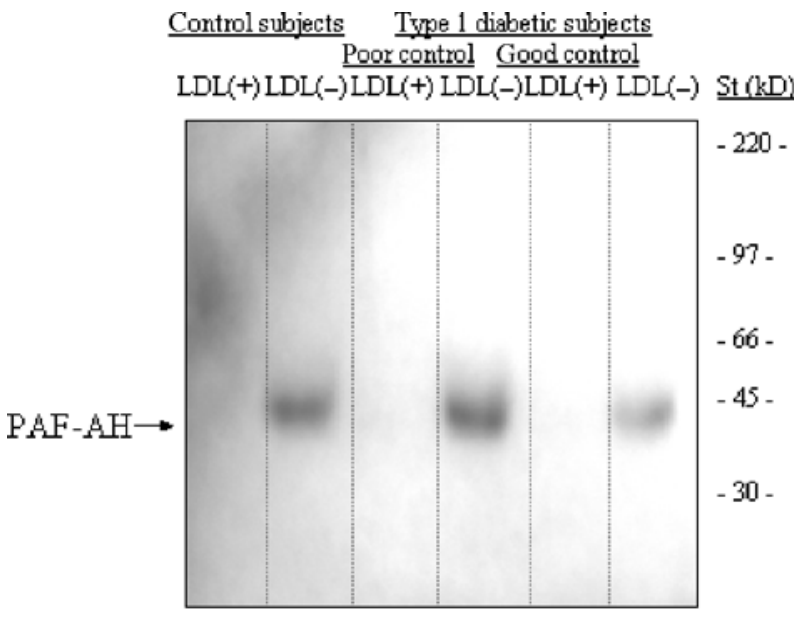

Fig. 2 Western blot analysis of LDL subfractions from control samples and type 1 diabetic samples before and after insulin therapy. Five micrograms of apoB were injected into each lane and SDSPAGE (4-20\%) electrophoresis developed as described in Subjects and Methods. Proteins were electrotransferred to a PVDF membrane and revealed with anti-PAF-AH antibody and HRP secondary antibody, as described in Subjects and Methods

differed from $\operatorname{LDL}(+)$ in the same components, i.e. increased content of triglyceride, NEFA, apoE and apoC-III and decreased relative content of apoB. ApoA-I and apoCII were not detectable and the contamination of $\mathrm{Lp}(\mathrm{a})$ was under 1 and $3 \%$ in $\operatorname{LDL}(+)$ and $\operatorname{LDL}(-)$, respectively, in all groups. No difference in composition was observed between control and type 1 diabetic samples or between good and poor glycaemic control.

No evidence of oxidative modification was observed in LDL $(-)$ in either group, as suggested by the lack of differences in antioxidant and MDA content (Table 3). These oxidative parameters were not modified after glycaemic optimisation. Moreover, LDL(-) was more resistant to oxidation than LDL(+) in control and type 1 diabetic samples, as indicated by longer lag-phase times (Table 3 ). PAF-AH activity was also increased in all LDL $(-)$ preparations (Table 3). Interestingly, optimisation of glycaemic control decreased both PAF-AH activity and lag-phase time in LDL(-) from type 1 diabetic samples. A decrease of PAF-AH was also observed when PAF-AH mass was semiquantitatively determined by Western blot analysis (Fig. 2). LDL particle size was similar in all studied samples and was not modified by glycaemic optimisation (Table 3 ). ApoB integrity of all LDL samples was confirmed by SDSPAGE (data not shown).

Cell viability of HUVEC cultures after incubation with LDLs or TNF- $\alpha$, measured by the LDH test, was over $92 \%$ in all experiments, and similar to that observed in control cells $(>95 \%)$. LDL $(-)$ from control and diabetic samples induced a 1.5- to 2-fold increase in the release of IL-8 and MCP-1 in cultured endothelial cells (Fig. 3). Neither MCP-1 nor IL-8 release decreased after glycaemic optimisation. Known positive inducers of chemokine production such as oxLDL and TNF- $\alpha$ induced a three- - to four-fold increase of IL-8 and MCP- 1 compared with LDL $(+)$.

After $4 \mathrm{~h}$ of incubation with LDLs or IL1 $\beta$, HUVEC increased the nuclear content of p65, p50 (both compo-
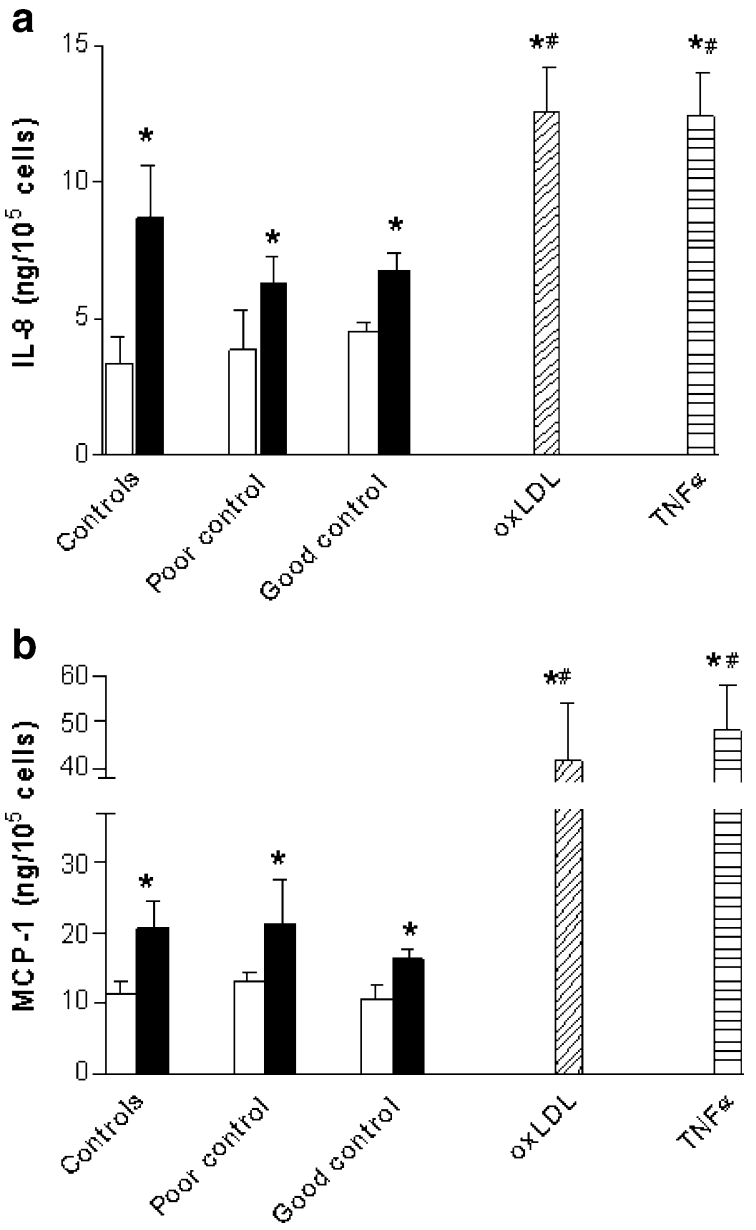

Fig. 3 Chemokine release from endothelial cells induced by LDL subfractions. HUVECs were incubated for $24 \mathrm{~h}$ at $37^{\circ} \mathrm{C}$ with LDL subfractions $(100 \mu \mathrm{g} / \mathrm{ml})$ of control and type 1 diabetic patients, as described in Subjects and Methods. IL-8 (a) and MCP-1 (b) were measured from culture media by ELISA. TNF- $\alpha(20 \mathrm{ng} / \mathrm{ml})$ and oxidised LDL (oxLDL; $100 \mu \mathrm{g} / \mathrm{ml}$ ) were used as positive controls. $\mathrm{LDL}(+)$, white bars; $\operatorname{LDL}(-)$, black bars. ${ }^{*} p<0.05$ vs $\operatorname{LDL}(+)$; ${ }^{\#} p<0.05$ vs LDL $(-)$

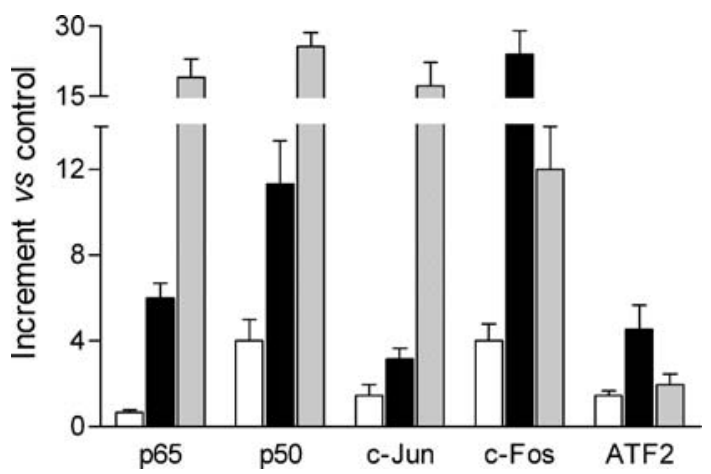

Fig. 4 Nuclear transcription factors stimulated by LDL(-). HUVECs were incubated for $4 \mathrm{~h}$ at $37^{\circ} \mathrm{C}$ with LDL subfractions $(100 \mu \mathrm{g} / \mathrm{ml})$ of type 1 diabetic patients or IL-1 $\beta(10 \mathrm{U} / \mathrm{ml})$. Using an ELISA-based method (see Subjects and Methods), $20 \mu \mathrm{g}$ of protein nuclear extracts were assayed. Results are expressed as increment versus control cells (unstimulated cells). LDL(+), white bars; LDL $(-)$, black bars; IL-1 $\beta$, grey bars 
nents of NF-kB), c-Fos, c-Jun and ATF2 (components of AP-1) (Fig. 4). LDL(-) increased by 9-, 3-, 2.5-, 6-and 3fold the concentration of p65, p50, c-Fos, c-Jun and ATF2, respectively, compared with the effect of $\operatorname{LDL}(+)$.

\section{Discussion}

The present study shows that LDL(-) isolated from shortduration type 1 diabetic patients behaves as an inflammatory lipoprotein since it induces the release of IL-8 and MCP-1 from cultured HUVEC. This proinflammatory and proatherogenic characteristic is shared with $\mathrm{LDL}(-)$ from healthy and hypercholesterolaemic subjects $[11,15,16]$. However, the exact mechanism by which LDL(-) induces chemokine release and the causes of its formation in plasma remain poorly understood.

Diabetic patients present a confluence of factors that could contribute to modifying the qualitative characteristics of lipoproteins. LDL from these subjects is exposed to increased non-enzymatic glycosylation, a process reported to be closely related to oxidation [29]. Our previous findings $[20,21]$ indicated that the increased proportion of LDL $(-)$ observed in type 1 diabetic patients decreases after optimisation of glycaemic control; hence, a feasible explanation for increased LDL(-) in these subjects could be increased non-enzymatic glycosylation of lipoproteins. However, current results rule out this possibility, since although both LDL subfractions from type 1 diabetic patients in poor glycaemic control presented increased glycation, no difference was observed between $\operatorname{LDL}(+)$ and LDL(-). Moreover, in vitro experiments revealed that a high level of glycation in LDL is required to achieve the electronegativity displayed by LDL(-). According to our data, Gambino et al. observed increased LDL electronegativity measured by capillary electrophoresis in type 1 diabetic patients, but found no correlation with glycaemic control parameters [30]. These findings clearly show that the increased electric charge of $\operatorname{LDL}(-)$ is not due to glycosylation of apoB but that additional physicochemical modifications should be present in $\operatorname{LDL}(-)$. Among these physicochemical factors, oxidative processes are unlikely to be involved since the measurement of lipid oxidation products or antioxidant content revealed no differences between $\operatorname{LDL}(+)$ and $\operatorname{LDL}(-)$, between control and type 1 diabetic patients or between poor and good glycaemic control. Supporting the lack of involvement of oxidative modification, LDL $(-)$ was more resistant to 'in-vitro'-induced oxidation than $\operatorname{LDL}(+)$. These features were previously observed in healthy and hypercholesterolaemic subjects [16]. A precise explanation for increased resistance to oxidation is not available but could be related to two characteristics of LDL(-). First, its high susceptibility to aggregation [16], since aggregated lipoproteins are known to be resistant to oxidative modification [31]. Second, the high PAF-AH activity observed in LDL $(-)$, since the hydrolysis of oxidised phospholipids has been reported to prevent oxidation of LDL [32]. Interestingly, glycaemic optimisation resulted in decreased $\operatorname{LDL}(-)$ proportion, decreased PAF-AH activity in LDL(-) and increased susceptibility to oxidation, thereby supporting the notion that PAF-AH plays a role in the prevention of LDL(-) oxidation. A further possibility is that the increased PAF-AH in LDL $(-)$ could be a consequence of a previous free radical injury suffered by LDL in plasma. Thus, the absence of increased oxidative markers in LDL(-) would not mean that these particles were not previously minimally oxidised, rather that PAF-AH could have stopped the development of oxidative reactions. Whatever the mechanism, both LDL subfractions from type 1 diabetic patients in poor glycaemic control were more resistant to in vitro oxidation than LDL subfractions from control subjects. This observation concurs with previous studies $[20,33,34]$ in which type 1 diabetic subjects with short diabetes duration were studied. LDL oxidisability appears to be related to the duration and severity of diabetic complications and, in contrast to type 2 diabetic patients, type 1 patients with short-duration diabetes should not have developed major complications.

Major compositional differences between $\operatorname{LDL}(+)$ and LDL(-) isolated from type 1 diabetic patients are the same as those observed in the current and previous studies [11, $15,16]$ in subfractions isolated from healthy subjects, i.e. LDL $(-)$ contains more triglyceride, NEFA, apoE, apoC-III and PAF-AH, and less apoB than $\mathrm{LDL}(+)$. This resemblance suggests that processes behind the formation of LDL (-) could be similar in diabetic and healthy subjects, with the cause of increased LDL(-) in diabetic subjects being merely a quantitative matter. It is generally accepted that atherosclerosis is accompanied by low-grade inflammation [35]. In this context, the current finding that increased PAFAH in LDL(-) decreases after glycaemic optimisation and the observation that PAF-AH activity is increased in diabetic patients $[36,37]$ points to underlying inflammation as a key factor in the generation of LDL(-) in diabetes. PAF$\mathrm{AH}$ expression increases in response to inflammatory stimuli and hyperglycaemia and insulin resistance are associated with low-grade systemic inflammation. Recent studies described low-grade inflammation in recently diagnosed type 1 diabetic subjects $[38,39]$ and associated these inflammatory markers with increased intima-media thickness [39]. Thus, although short-course type 1 diabetic patients should not present advanced atherosclerotic plaques, the existence of incipient lesions could also contribute to accelerating inflammatory processes.

Our results suggest a role for PAF-AH or its catabolic products, short-chain NEFA and/or lysophosphatidylcholine, in the chemokine release mediated by LDL(-) from type 1 diabetic subjects. This proinflammatory action may be mediated by the activation of transcription factors such as NF-kB and/or AP-1, since several of their components (p65 and p50 for NF-kB; c-Jun, c-Fos and ATF2 for AP-1) increase their nuclear concentration in response to LDL(-).

In conclusion, our results indicate that $\operatorname{LDL}(-)$ isolated from type 1 diabetic patients is proinflammatory and that PAF-AH could play a major role in its inflammatory activity. Insulin therapy promoted a decrease in LDL $(-)$ proportion and decreased its PAF-AH content, thereby suggesting that normalisation of glycaemic control could 
contribute to a reduction of the atherosclerotic risk arising from modified LDL. Nevertheless, further studies are required to elucidate the exact role of $\operatorname{LDL}(-)$ in the accelerated atherogenesis present in diabetes.

Acknowledgements This work was supported by grants from La Marató de TV3, CICYT SAF98/0125 and MCYT SAF2001-0480 from the Ministerio de Ciencia y Tecnologia and C03/01, C03/08 and PI-030885 from FIS. The authors are grateful to Christine O'Hara for editorial assistance.

\section{References}

1. The DCCT Research Group (1992) Lipid and lipoprotein levels in patients with insulin-dependent diabetes mellitus: the Diabetes Control and Complications Trial (DCCT) experience. Diabetes Care 15:886-894

2. Assmann G, Schulte H (1988) The prospective cardiovascular Munster (PROCAM) study. Prevalence of hyperlipidemia in persons with hypertension and/or diabetes mellitus and the relationship to coronary heart disease. Am Heart J 116:17131724

3. Navab M, Berliner JA, Watson AD et al (1996) The Yin and Yang of oxidation in the development of the fatty streak. Arterioscler Thromb Vasc Biol 16:831-842

4. Scheffer PG, Henry RMA, Wever EJM et al (2004) LDL oxidative modifications in well- or moderately controlled type 2 diabetes. Diabetes/Metab Res Rev 20:298-304

5. Kim HJ, Kurup IV (1982) Nonenzymatic glycosylation of human low density lipoprotein; evidence for in vivo and in vitro glycosylation. Metabolism 31:348-352

6. Sobenin IA, Tertov VV, Koschinski T et al (1993) Modified low density lipoprotein from diabetic patients causes cholesterol accumulation in human intimal aortic cells. Atherosclerosis 100:41-54

7. Caixàs $A$, Ordóñez-Llanos $J$, de Leiva A, Payés A, Homs R, Pérez A (1997) Improvement of glycemic control in diabetes decreases the atherogenic small dense LDL particles. Diabetes 46:1207-1213

8. Avogaro P, Bittolo-Bon G, Cazzolato G (1988) Presence of a modified low density lipoprotein in humans. Arteriosclerosis 8:79-87

9. Sánchez-Quesada JL, Benítez S, Ordóñez-Llanos J (2004) Electronegative low-density lipoprotein. Curr Opin Lipidol 15: 329-335

10. Sánchez-Quesada JL, Benítez S, Franco M, Otal C, BlancoVaca F, Ordóñez-Llanos J (2002) Density distribution of electronegative LDL (LDL $(-)$ ) in normolipemic and hyperlipemic subjects. J Lipid Res 43:699-705

11. Benítez S, Ordóñez-Llanos, Franco M et al (2004) Effect of simvastatin in familial hypercholesterolemia on the affinity of charge-differing low-density lipoprotein subfractions to the low-density lipoprotein receptor. Am J Cardiol 93:414-420

12. Hodis HN, Kramsch DM, Avogaro P et al (1994) Biochemical and cytotoxic characteristics of an in vivo circulating oxidised low-density lipoprotein (electronegative LDL). J Lipid Res 35:669-677

13. Demuth K, Myara I, Chappey B et al (1996) A cytotoxic electronegative LDL subfraction is present in human plasma. Arterioscler Thromb Vasc Biol 16:773-783

14. Chen CH, Jiang T, Yang JH et al (2003) Low-density lipoprotein in hypercholesterolemic human plasma induces vascular endothelial cell apoptosis by inhibiting fibroblast growth factor 2 transcription. Circulation 107:2102-2108

15. de Castellarnau C, Sánchez-Quesada JL, Benítez S et al (2000) Electronegative LDL from normolipemic subjects induces IL-8 and monocyte chemotactic protein secretion by human endothelial cells. Arterioscler Thromb Vasc Biol 20:2281-2287
16. Sánchez-Quesada JL, Camacho M, Antón R, Benítez S, Vila L, Ordóñez-Llanos J (2003) Electronegative LDL of FH subjects. Chemical characterization and induction of chemokine release from human endothelial cells. Atherosclerosis 166:261-270

17. Ziouzenkova O, Asatryan L, Sahady D et al (2003) Dual roles for lipolysis and oxidation in peroxisome proliferation-activator receptor responses to electronegative low density lipoprotein. J Biol Chem 278:39874-39881

18. Sánchez-Quesada JL, Otal-Entraigas C, Franco M et al (1999) Effect of simvastatin treatment on the electronegative lowdensity lipoprotein present in patients with familial hypercholesterolemia. Am J Cardiol 84:655-659

19. Ziouzenkova O, Asatryan L, Akmal M et al (1999) Oxidative cross-linking of apoB100 and hemoglobin results in low density lipoproteins modification in blood. J Biol Chem 27:18916-18924

20. Sánchez-Quesada JL, Pérez A, Caixàs A et al (1996) Electronegative low-density lipoprotein subform is increased in patients with short-duration IDDM and is closely related to glycaemic control. Diabetologia 39:1469-1476

21. Sánchez-Quesada JL, Pérez A, Caixàs A et al (2001) Effect of glycemic optimization on electronegative low-density lipoprotein in diabetes: relation to nonenzymatic glycosylation and oxidative modification. J Clin Endocrinol Metab 86:3243-3249

22. Moro E, Zambón C, Pianetti S, Cazzolato G, Pais M, Bittolo Bon G (1998) Electronegative low density lipoprotein subform is increased in type 2 (non-insulin-dependent) microalbuminuric patients and is closely associated with LDL susceptibility to oxidation. Acta Diabetol 35:161-164

23. Moro E, Alessandrini P, Zambón C et al (1999) Is glycation of low density lipoproteins in patients with Type 2 diabetes mellitus a LDL pre-oxidative condition? Diabet Med 16:663669

24. National Diabetes Data Group (1979) Classification and diagnosis of diabetes mellitus and other categories of glucose intolerance. Diabetes 28:1039-1057

25. Sánchez-Quesada JL, Ortega H, Payés-Romero A et al (1997) LDL from aerobically-trained subjects shows higher resistance to oxidative modification than LDL from sedentary subjects. Atherosclerosis 132:207-213

26. Fukunaga K, Suzuki T, Takama K (1993) Highly sensitive highperformance liquid chromatography for the measurement of malondialdehyde in biological samples. J Chromatogr 621:7781

27. Khoo J, Miller E, McLaughlin P, Steinberg D (1988) Enhanced macrophage uptake of low-density lipoprotein after self-aggregation. Arteriosclerosis 8:348-358

28. Benítez S, Sánchez-Quesada JL, Ribas V et al (2003) Plateletactivating factor acetylhydrolase is mainly associated with electronegative LDL subfraction. Circulation 108:92-96

29. Lyons TJ (1991) Oxidized low density lipoproteins: a role in the pathogenesis of atherosclerosis in diabetes? Diabet Med 8:411-419

30. Gambino R, Giunti S, Uberti B, Perin PC, Pagano G, Cassader M (2003) LDL electronegativity is enhanced in type 1 diabetes. Diabetes Care 26:2214-2215

31. Hermann M, Gneimer B (1992) Altered susceptibility to in vitro oxidation of LDL in LDL complexes and LDL aggregates. Arterioscler Thromb 12:1503-1506

32. Noto H, Hara M, Karasawa K et al (2003) Human plasma platelet-activating factor acetylhydrolase binds to all the murine lipoproteins, conferring protection against oxidative stress. Arterioscler Thromb Vasc Biol 23:829-835

33. Jenkins AJ, Klein RL, Chassereau CN, Hermayer KL, LopesVirella MF (1996) LDL from patients with well-controlled IDDM is not more susceptible to in vitro oxidation. Diabetes 45:762-767

34. Feillet C, Roche B, Tauveron I et al (1998) Susceptibility to oxidation and physicochemical properties of LDL in insulindependent diabetics. Atherosclerosis 136:405-407

35. Ross R (1999) Atherosclerosis - an inflammatory disease. N Engl J Med 340:115-126 
36. Winkler K, Abletshauser C, Friedrich I, Hoffmann MM, Wieland H, Marz W (2004) Fluvastatin slow-release lowers platelet-activating factor acetylhydrolase activity: a placebocontrolled trial in patients with type 2 diabetes. J Clin Endocrinol Metab 89:1153-1159

37. Serban M, Tanaseanu C, Kosaka T et al (2002) Significance of platelet-activating factor acetylhydrolase in patients with noninsulin dependent (type 2) diabetes mellitus. J Cell Mol Med 6:643-647
38. Scholin A, Siegbahn A, Lind L et al (2004) CRP and IL-6 concentrations are associated with poor glycemic control despite preserved B-cell function during the first year after diagnosis of type 1 diabetes. Diabetes/Metab Res Rev 20:205210

39. Mangge H, Schauenstein K, Stroedter L, Griesl A, Maerz W, Borkenstein M (2004) Low grade inflammation in juvenile obesity and type 1 diabetes associated with early signs of atherosclerosis. Exp Clin Endocrinol Diabetes 112:378-382 